\title{
THE EFFECTS OF POPLAR BARK AND WOOD CONTENT ON THE MECHANICAL PROPERTIES OF WOOD-POLYPROPYLENE COMPOSITES
}

\author{
Vahidreza Safdari, ${ }^{\text {a,* }}$ Hamed Khodadadi, ${ }^{\text {a }}$ Seyyed Khalil Hosseinihashemi, ${ }^{\text {a }}$ and \\ Esmaiel Ganjian ${ }^{\text {b }}$
}

\begin{abstract}
Bark, as a residue from trees, is mostly used for thermal energy production, but a better utilization of this resource was considered as an alternative raw material for wood-plastic composites (WPCs). The influence of bark, wood, and blending of bark and wood flour content of the poplar tree on the mechanical characteristics of WPCs were investigated. Wood and bark flours with $2 \%$ maleic anhydride-grafted polypropylene (MAPP) and polypropylene were compounded into pellets using a counter-rotating twin-screw extruder, and test specimens were prepared by injection molding. The results showed that both bark fiber and wood flour increased mechanical strength (flexural strength (MOR), flexural modulus (MOE), tensile modulus, and tensile strength) significantly $(\mathrm{P}<0.05)$. Composites made with bark flour exhibited lower mechanical strength compared to those made with wood flour and wood flour/bark flour. Differences in chemical composition between bark and wood, fines, low aspect ratio (length/width) of bark flour, delamination between fines and matrix, and the lower intrinsic fiber strength of bark fibers compared to wood fibers are good explanations for this demarcation. The notched impact strength of all reinforced composites was significantly lower than neat polypropylene $(P<0.05)$.
\end{abstract}

Keywords: Wood-plastic; Bark flour (fiber); Wood flour (fiber); Mechanical strength; Poplar wood

Contact information; a: Department of Wood and Paper Science, Karaj Branch, Islamic Azad University, Karaj, Iran; b: Department of Built Environment, Coventry University, UK, CV1 5FB; * Corresponding author: vahid.safdari@kiau.ac.ir /

vahid.safdari@gmail.com

\section{INTRODUCTION}

In wood-plastic composites (WPCs) the addition of a natural fiber, such as a reinforcing fiber or filler, results in a new material that performs much better than the individual components and provides a cost reduction of WPCs relative to the plastic alone. Wood-derived fillers or reinforcements are most commonly used in the WPCs industry due to wood fibers' suitable morphological characteristics (Stark and Rowlands 2003; Basiji et al. 2010), widespread availability, and their ability to be renewed (Rowell et al. 1997).

The roles of a coupling agent in wood fiber-reinforced plastic composites are very significant, as they can improve compatibility and adhesion between polar wood fibers and non-polar polymers. The influence of maleic anhydride-polypropylene (MAPP) as a 
coupling agent on the mechanical properties of polypropylene/hardwood flour prove that the composites display better properties at 5 lower total percentage weight of MAPP (Bledzki et al. 2002).

The effect of different lignocellulosic materials on mechanical characteristics of WPCs has been studied by many researchers, but the use of bark as a thermoplastic filler has not been evaluated much. The bark is the outer part of the tree stems and branches, and anatomically it is comprised predominantly of parenchyma on the inner side and contains periderm (cork) in its outer side. Bark is not as fibrous as woody parts (xylem) of a tree, and its proportion of fibers is lower than that of woods. Its morphology and chemical composition are different from wood as well (Harkin and Rowe 1971).

Bark, as a residue, is mostly used for thermal energy production (Klasnja et al. 2002; Yemele et al. 2008), but a better utilization of this resource can be as an alternative raw material for particleboard (Blanchet et al. 2000; Yemele et al. 2008), medium fiberboard (Xing et al. 2006), or WPCs (Harper and Eberhardt 2010; Yemele et al. 2010). All these alternatives were investigated in this research.

Yemele et al. (2010) found that most mechanical properties, e.g. strength except for tensile toughness and strain at failure, were lower for spruce bark plastic (HPDE) compared to the control WPC (neat HPDE). The reduction of the mechanical characteristics of bark plastic composites were reported by other researchers (Harper and Eberhardt 2010; Bouafif et al. 2009). In addition to the mechanical characteristics, the physical characteristics of bark-plastic materials are also different from wood-plastic materials. For example, by increasing the bark content the water absorption and thickness swelling of composites were decreased (Kazemi Najafi et al. 2008; Bouafif et al. 2009).

Amongst the many factors that affect the mechanical and physical properties of composites, the fiber contents are a salient factor (Bledzki et al. 1998). In wood-plastic composites, increasing the fiber loadings initially lead to an increase in some of the mechanical properties (Basiji et al. 2010; Bouafif et al. 2009). However, with further increase of the weight percentage of the wood fillers to WPCs, an optimum percentage is reached, and there is no value in further increasing the content of wood fillers ( $\mathrm{Lu}$ et al. 2005).

Thus it seems that bark-plastic composites could meet the usual performance requirements if the uses of bark flour have an optimized content in blending with the wood flour. In order to evaluate the effect of the bark flour content on the mechanical characteristics of WPCs the bark of poplar wood was selected. The genus Populus is a fast-growing tree that belongs to the Salicaceae family, which comprises of more than 100 species that are distributed in temperate and subtropical regions (Wang et al. 1999).

In this research the effects of poplar bark flour content on the mechanical properties of wood polypropylene composites were studied.

\section{EXPERIMENTAL}

\section{Materials}

Four logs $(1 \mathrm{~m}$ ) from the poplar tree (Populus nigra L. var. pyramidalis (Rozier) Spach) were cut at breast height and sawn to boards with $2.5 \mathrm{~cm}$ thickness and stored at 
room temperature $\left(20-24{ }^{\circ} \mathrm{C}\right)$. A total of $14.2 \%$ bark residues were found in the poplar tree based on the oven-dry weight. The oven-dry densities of the bark and wood were determined by a volumetric method, and they were found to be $530 \mathrm{~kg} / \mathrm{m}^{3}$ and $450 \mathrm{~kg} / \mathrm{m}^{3}$, respectively. The chemical composition of the wood and bark including cellulose, lignin, cold and hot water extractives, organic, and inorganic material contents were calculated according to TAPPI standards (T 17 wd-70, T 222 om-98; T 207 cm-99; T 204 cm-97 and $\mathrm{T} 211 \mathrm{om}-93)$.

The wood and bark were cut into small pieces and chopped using a laboratory electrical rotary mill to get wood and bark flours (WF and BF). The flour size was between 40 and 60 mesh. The slenderness ratio, or in other words, the fibers length to diameter ratio $(L / D)$ class was obtained by means of a light microscope equipped with a reticle cross-hair eyepiece. As can be seen, the particles in the bark were finer than in the wood (Fig. 1). The WF and BF were dried in an oven at $103 \pm 2{ }^{\circ} \mathrm{C}$ for 24 hours to reach $0 \%$ moisture content and then stored in sealed plastic bags until blending with polypropylene.
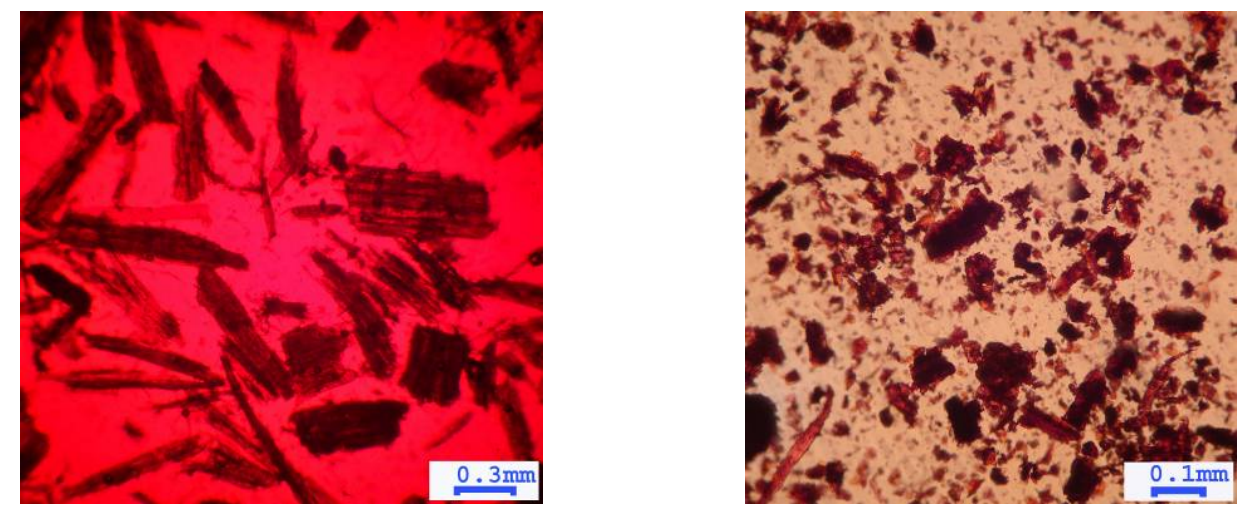

Figure 1. (Left) Wood flour (WF) and (Right) Bark flour (BF). The flour of bark was composed of fines and slenderness ratio of BF was lower than WF (see Table 2).

Homopolymer polypropylene (PP) was obtained from Arak Petrochemical Company (Iran). The melt flow rate of PP (trade name P10800) was 7 to $10 \mathrm{~g}$ per 10 min at $190{ }^{\circ} \mathrm{C}$. Maleic anhydride-grafted polypropylene (MAPP: Aldrich 427845) was used as a coupling agent. Polypropylene, MAPP, BF, and WF were used according to the different contents listed in Table 1.

\section{Composite Preparation}

The components of each sample (PP, MAPP, WF, and BF) were pre-mixed according to Table 1, and homogeneous compounds were prepared and blended in a counter-rotating twin-screw extruder (Dr. Collin System) at a screw speed of $50 \mathrm{rpm}$ at $180^{\circ} \mathrm{C}$.

The mix was removed from the mixing bowl, cooled in water, and granulated into pellets. The pellets were dried at $105{ }^{\circ} \mathrm{C}$ for $24 \mathrm{~h}$ before injection molding was done. Finally, the pellets were injection molded (Imen Machine Co., Iran) at $175^{\circ} \mathrm{C}$ and at a pressure of $10 \mathrm{MPa}$. 


\section{Mechanical Testing}

All of the composites samples were kept at $23{ }^{\circ} \mathrm{C}$ and $50 \%$ humidity before mechanical testing. The flexural testing including flexural strength (MOR) and flexural modulus (MOE) were performed on an Instron 1186 universal testing machine, according

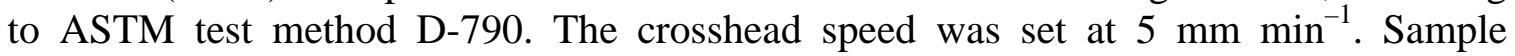
dimensions for flexural tests were $105 \times 10 \times 10 \mathrm{~mm}$.

The tensile properties of each specimen were tested with an INSTRON 1186 universal testing machine, according to the ASTM test method D-638. The sample dimensions for tensile property testing were $145 \times 10 \times 4 \mathrm{~mm}$.

The notched Izod impact strength test was conducted with a SANTAM machine, according to ASTM test method D-256. The sample dimensions for the notched Izod impact test were $60 \times 12 \times 6 \mathrm{~mm}$.

\section{Statistical Analysis}

Statistical analysis was performed using ANOVA (SPSS). The 10 formulation designs, which are shown in Table 1 , were all analyzed for variance using a complete randomized block design. Testing of mechanical properties was performed using 4 replicates of each formulation. Property means were compared using Duncan's new multiple range test at the 95\% confidence level, as shown in Fig. 2-7.

Table 1. Experimental Design for Bark and Wood-Plastic Composites Formulations

\begin{tabular}{|c|c|c|c|}
\hline $\begin{array}{c}\text { WF } \\
(w t \%)\end{array}$ & $\begin{array}{c}\text { BF } \\
(w t \%)\end{array}$ & $\begin{array}{c}(P P) \\
(w t \%)\end{array}$ & $\begin{array}{c}\text { MAPP } \\
(w t \%)\end{array}$ \\
\hline 0 & 23 & 75 & 2 \\
\hline 0 & 33 & 65 & 2 \\
\hline 0 & 43 & 55 & 2 \\
\hline 11.5 & 11.5 & 75 & 2 \\
\hline 16.5 & 16.5 & 65 & 2 \\
\hline 21.5 & 21.5 & 55 & 2 \\
\hline 23 & 0 & 75 & 2 \\
\hline 33 & 0 & 65 & 2 \\
\hline 43 & 0 & 55 & 2 \\
\hline 0 & 0 & 100 & 0 \\
\hline
\end{tabular}

$\mathrm{WF}=$ Wood flour; $\mathrm{BF}=$ Bark flour; $\mathrm{PP}=$ polyethylene; $\mathrm{MAPP}=$ polyethylene maleic anhydride

\section{Scanning Electron Microscope Images of Natural Wood and Bark and Fracture Surface of Composites}

Scanning electron microscopy (SEM) was used to monitor the fracture surface of the composites. SEM analysis was performed using a Philips XL30 (Holland) instrument. The samples were sputtered with a layer of gold/palladium before imaging. Meanwhile, wood samples inclusions of bark were also photographed by SEM (Exley et al. 1974). Before using the SEM, the cross-sections of samples $(1 \times 1 \times 1 \mathrm{~cm})$ were smoothed by sliding microtome, and many micro layers were removed from the samples. 


\section{RESULTS AND DISCUSSION}

\section{Chemical Characteristics}

The organic (cellulose, lignin, extractives) and inorganic (ash) content of wood and bark of poplar were determined and are presented in Table 2. Bark has a lower cellulose content, higher lignin content, and higher hot and cold water extractives than wood. Bark also has a higher inorganic content, mainly due to the presence of silica (Yemele et al. 2010).

Table 2. Chemical Properties of Wood and Bark of the Poplar

\begin{tabular}{|c|c|c|c|c|c|c|c|c|c|}
\hline & \multicolumn{6}{|c|}{ Chemical Characteristics } & \multicolumn{3}{c|}{ Fiber Sizes } \\
\cline { 2 - 9 } Poplar & $\begin{array}{c}\text { Cellulose } \\
(\%)\end{array}$ & $\begin{array}{c}\text { Ash } \\
(\%)\end{array}$ & $\begin{array}{c}\text { Lignin } \\
(\%)\end{array}$ & $\begin{array}{c}\text { Hot } \\
\text { water } \\
(\%)\end{array}$ & $\begin{array}{c}\text { Cold } \\
\text { water } \\
(\%)\end{array}$ & $\begin{array}{c}\text { Organic } \\
(\%)\end{array}$ & $\begin{array}{c}\text { L } \\
(\mathrm{mm})\end{array}$ & $\begin{array}{c}\mathrm{D} \\
(\mathrm{mm})\end{array}$ & $\begin{array}{c}\text { Slenderness } \\
\text { ratio } \\
(\mathrm{L} / \mathrm{D})\end{array}$ \\
\hline Wood & 46.66 & 2.06 & 22.33 & 6 & 5 & 4.1 & 0.30 & 0.05 & 5.3 \\
\hline Bark & 24.33 & 12.22 & 33 & 23.5 & 14.5 & 13 & 0.15 & 0.05 & 2.7 \\
\hline
\end{tabular}

$\mathrm{L}=$ mean length; $\mathrm{D}=$ mean diameter

\section{Relationship between Compositions and Mechanical Properties}

Flexural strength and flexural modulus

As shown in Figs. 2 and 3, MOR and MOE, values ranged from 28.77 MPa to 43.39 $\mathrm{MPa}$ and 1148.50 MPa to 2194.0 MPa, in reinforced composites, respectively. The composites $\mathrm{BF} / \mathrm{PP}$ exhibited the lowest MOR and MOE. Amongst the BF/PP conditions, the $23 \% \mathrm{BF}$ content showed the lowest MOR and was significantly different from the treatments having more BF content. By increasing the BF content from 23\% to 33\% and $43 \%$ the MOR and MOE characteristics increase significantly. Among the BF/PP composites, the optimum content for improving the flexural and modulus strength was found to be $43 \%$. But the values for BF/PP were not much different from those for neat $\mathrm{PP}$. Thus, the BF acted more as composite filler rather than as a reinforcing agent. Yemele et al. (2010) found the same trend also.

The low effect of BF on flexural strength can be attributed to fines and low aspect ratio (length/width) of BF in PP matrix (Migneault et al. 2009), the lower intrinsic fiber strength of bark fibers compared to wood fibers (Yemele et al. 2010), lower cellulose (polysaccharide) content of the bark fillers than wood (Harper and Eberhardt 2010), and delaminating between fines and PP (Fig. 9). Higher amounts of extractives in bark cause a weak surface layer and make the coupling agent less effective in forming a crosslinking network with the cellulose (Saputra et al. 2004).

When the BF was blended with WF, the flexural modulus increased compared to the composites that contained only BF. In all treatments by increasing the flour content, the flexural modulus strength recovered. For example, despite the fact that some compositions used were blended with WF/BF/PP such as 55\% PP $+21.5 \% \mathrm{BF}+21.5 \% \mathrm{WF}$, the flexural strengths didn't show a significant difference with some compositions that used WF/PP (65\% PP + 33\% WF). This can be attributed to the fiber content. The content of 
fiber in later composition was lower than the former composition; however as there was a better quality of WF compared to BF, the lower fiber content was compensated. This results in there being no significant differences between the two composites.

Amongst the compositions having mixtures of BF/WF/PP together, the composite of $55 \% \mathrm{PP}+21.5 \% \mathrm{BF}+21.5 \% \mathrm{WF}$ that had the highest flour content also had greater flexural and modulus strength. The composites of WF/PP showed the highest flexural modulus strength, and it comprised 55\% PP + 43\% WF; these results showed significant difference with all the other treatments. In composites of 55\% PP $+43 \% \mathrm{BF}$, despite their having a higher content of BF, their flexural strength was lower than other treatments with lower content of WF or WF/BF. This proves that fiber content cannot be the sole important factor in increasing the flexural strength, and other factors, i.e., morphological and chemical characteristics of fibers and intrinsic fiber strength should be considered.

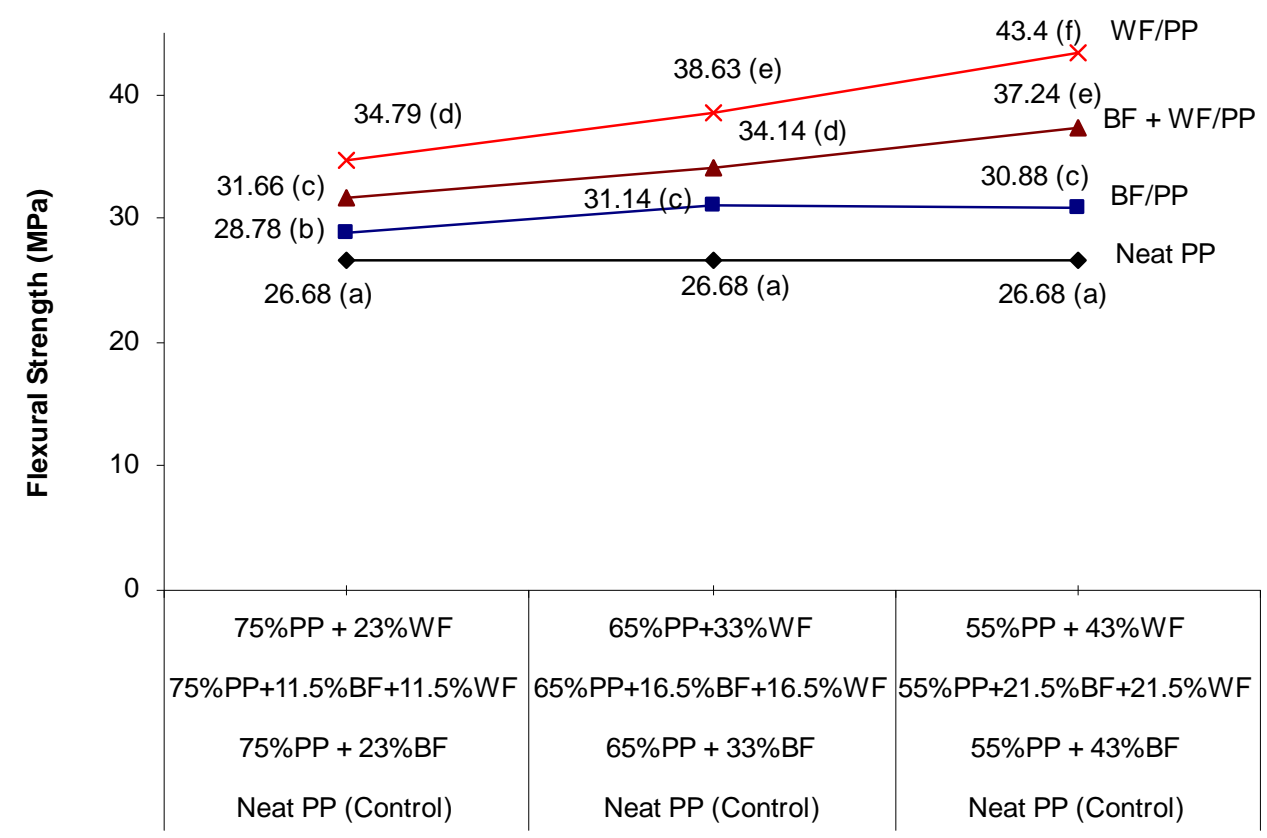

Figure 2. Mean values of the BF/PP, BF/WF/PP, and WF/PP composites. Duncan's multiple range tests are given in the parentheses. The different alphabetical designations indicate that there is a significant difference between different treatments (composites), whereas the common alphabetical designation indicates there are no significant differences $(P<0.05)$. By adding WF to the composites and by increasing the flour content the MOR increases.

\section{Tensile Strength and Tensile Modulus}

As shown in Figs. 4 and 5, the tensile strength and tensile modulus ranged from 21.47 $\mathrm{MPa}$ to 32.66 MP and 1684.67 $\mathrm{MPa}$ to 4417.33 in reinforced composites, respectively. As in the case of flexural strength, the tensile strength of those composites that had been prepared with BF/PP was lower than other composites. Composites comprising WF/PP showed the best tensile strength and tensile modulus among all other 
compositions. The composites having more than 33\% BF (i.e. 43\% BF) and lower than $33 \%$ BF (i.e. $23 \% \mathrm{BF}$ ) were not significantly different to each other with respect to tensile strength. Among the $\mathrm{BF} / \mathrm{PP}$ composites, the optimum content for improving the tensile strength and tensile modulus was 33\%.

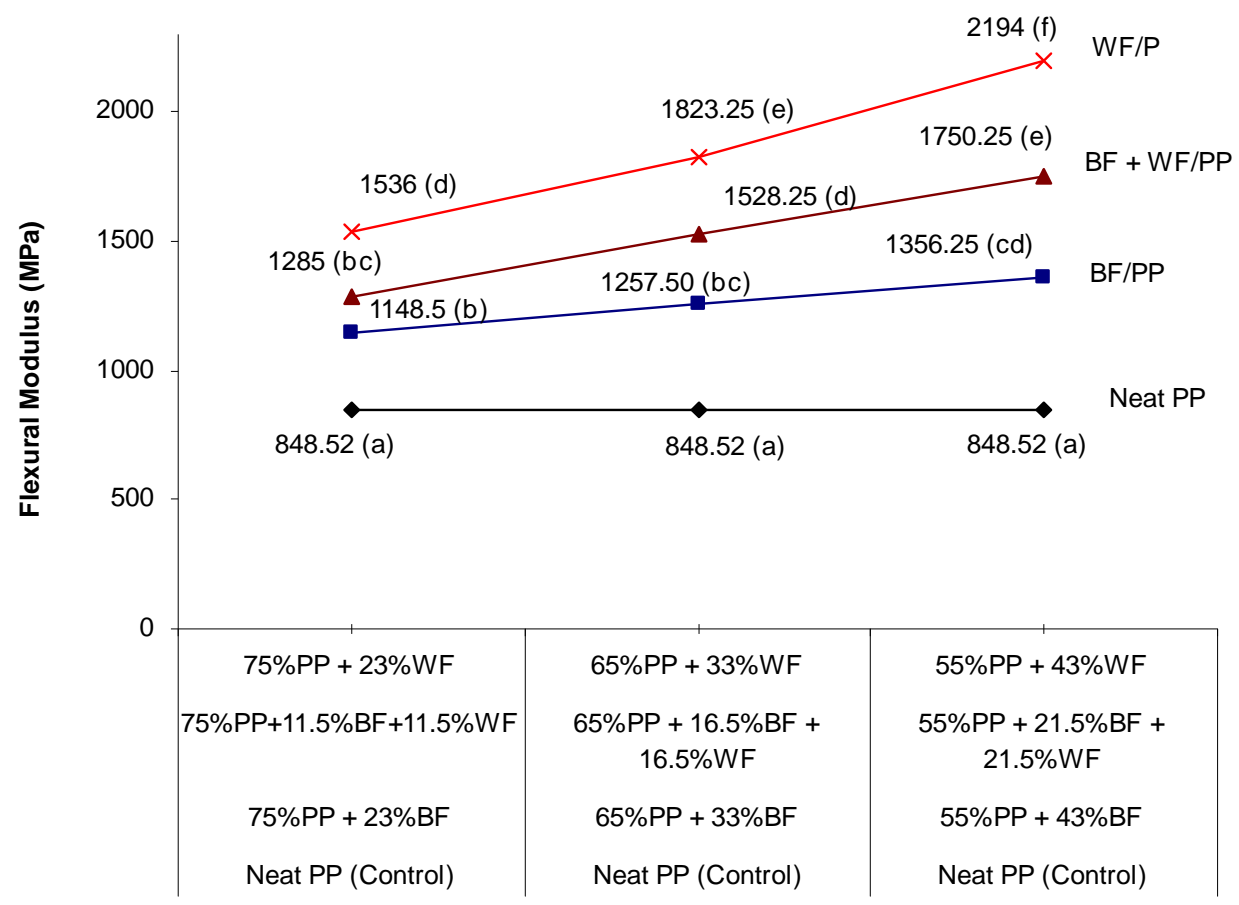

Figure 3. Mean values of the MOE of BF/PP, BF/WF/PP, and WF /PP composites. Duncan's multiple range tests are given in parentheses. The different alphabetical designations indicate that there is a significant difference between different treatments (composites), whereas the common alphabetical designation indicates no significant difference $(P<0.05)$. By adding WF to the composites and by increasing the flour content the MOE increases.

The weak effectiveness of BF in comparison to WF with respect to tensile strength could be due to the low slenderness ratio of bark fibers (Stark and Rowlands 2003), poor fine fiber dispersion in the plastic matrix, resulting in stress concentration (Gamstedt et al. 2007), and lower intrinsic fiber strength of bark fibers compared to wood fibers. Poor bark-plastic adhesion between bark fiber and the coupling agent was reported by some researchers and can be one of the reasons that may account for lower tensile strength (Bouafif et al. 2008 and 2009).

Increasing the WF content increased the tensile strength. The composition 55\% $\mathrm{PP}+43 \% \mathrm{BF}$, had higher flour content than 75\% PP + 11.5\% BF + 11.5\% WF; however due to the presence of WF in the former composition, the tensile strength was signifycantly higher. This proves that the effect of fiber content on mechanical properties is dependent on the intrinsic fiber strength and fiber size. These results are in good agreement with results from other researchers that reported by increasing the particle size (Stark and Berger 1997) or, slenderness ratio, flexural and tensile modulus and strength tend to increase (Stark and Rowlands 2003). 


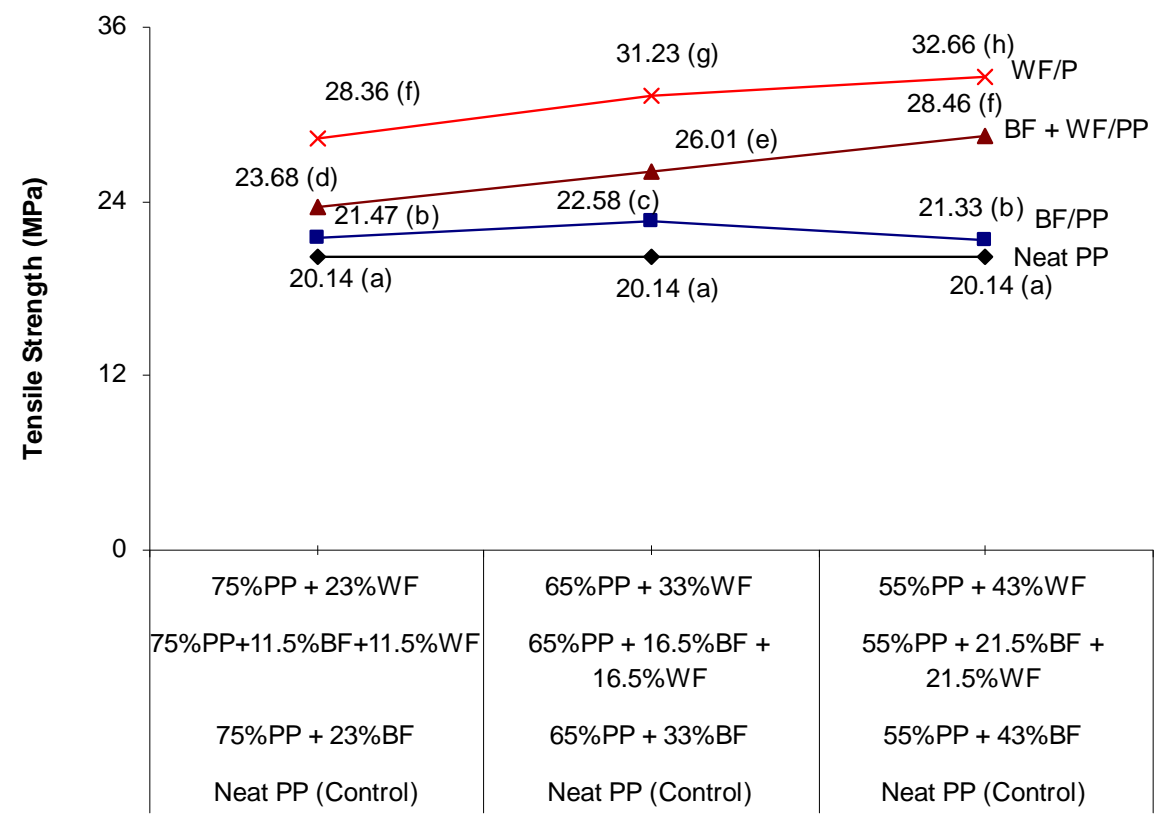

Figure 4. Mean values of the tensile strength of BF/PP, BF/WF/PP, and WF/PP composites. Duncan's multiple range tests are given in parentheses. The different alphabetical designations indicate that there is a significant difference between different treatments (composites), whereas the common alphabetical designation indicates no significant difference $(P<0.05)$. By adding the WF to composites and by increasing the flour content the tensile strength increases.

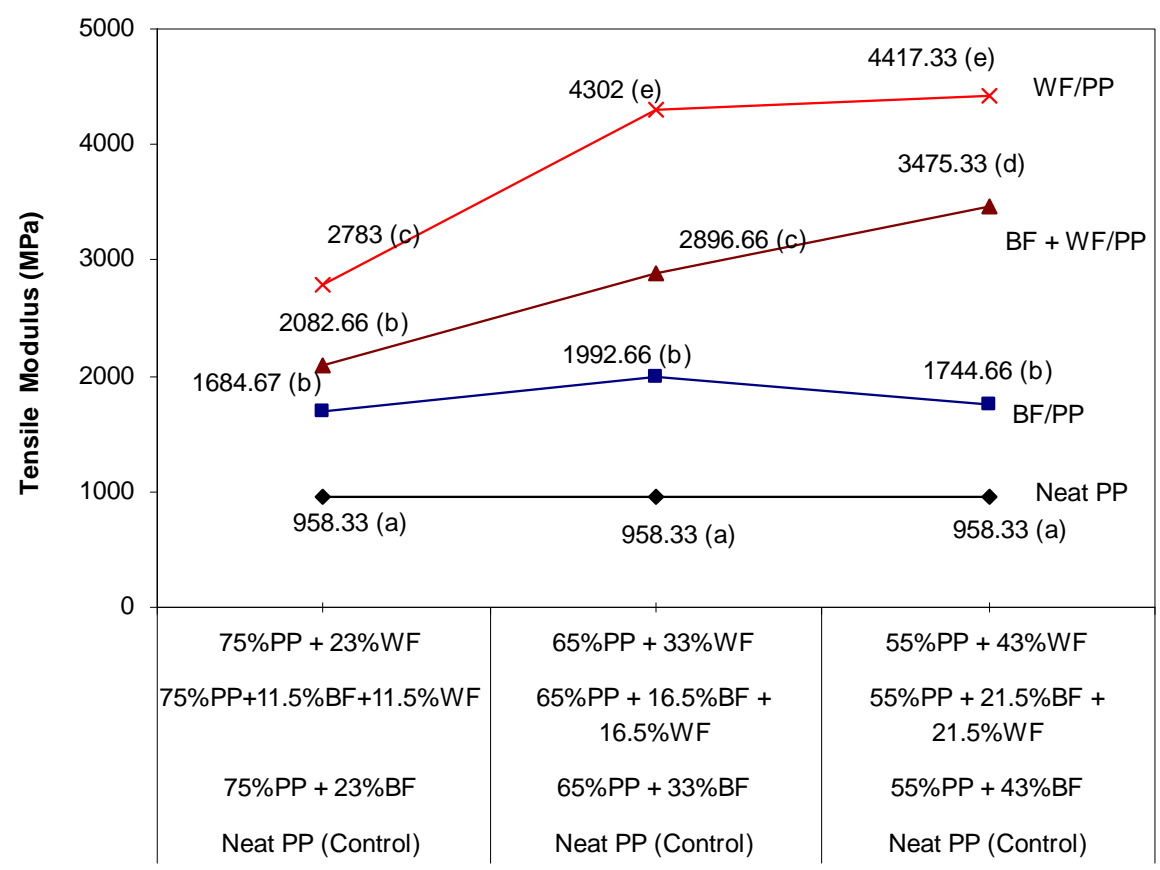

Figure 5. Mean values of the tensile Modulus of BF/PP, BF/WF/PP, and WF/PP composites. Duncan's multiple range tests are given in parentheses. The different alphabetical designations indicate that there is a significant difference between different treatments (composites), whereas the common alphabetical designation indicates no significant difference $(P<0.05)$. By adding the WF to composites and by increasing the flour content the tensile modulus increases. 


\section{Impact}

As shown in Fig. 6, the impact strength ranged from $25.11 \mathrm{~J}^{-1}{ }^{-1}$ to $44.74 \mathrm{~J}^{-1}$. The impact strength results were in contradiction to the other strengths such as MOR, MOE, tensile strength, and tensile modulus. Compositions containing less flour and more polypropylene (75\% PP) had higher impact strength. This was attributed to the lack of compatibility between the phases and also the addition of bio-resource fiber content creates regions of stress concentration that require less energy to initiate a crack in samples (Rowel et al. 1997). Thus the composites reinforced with lignocellulosic material were more brittle and exhibited lower notched impact strength.

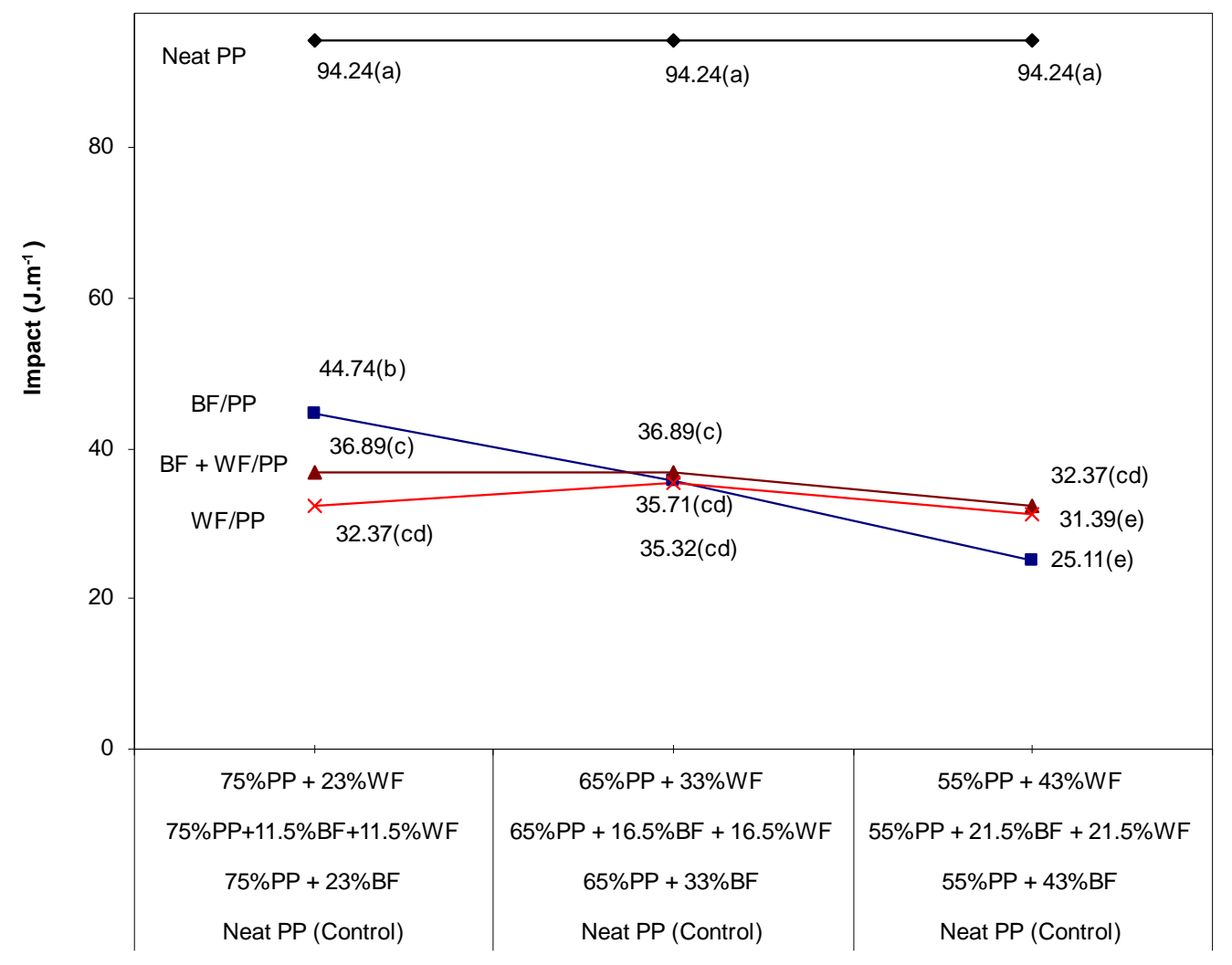

Figure 6. Mean values of the impact strength of BF/PP, BF/WF/PP, and WF/PP composites. Duncan's multiple range tests are given in parentheses. The different alphabetical designations indicate that there is a significant difference between different treatments (composites), whereas the common alphabetical designation indicates no significant difference $(P<0.05)$. By adding WF to the composites and by increasing the flour content the notched impact strength decreases.

\section{Composites Density}

Mean values of the density of reinforced composites ranged from 0.85 to 0.88 $\mathrm{g} / \mathrm{cm}^{3}$. There was significant difference between all composites with neat PP $(0.82$ $\mathrm{g} / \mathrm{cm}^{3}$ ), but reinforced composites did not have any significant difference between each other. Despite a lack of significant difference between reinforced composites, those composites with $43 \%$ flour had higher density than those containing less (i.e. $23 \%$ and $33 \%$ flour). Thus adding flour increased density in comparison to neat polypropylene. 


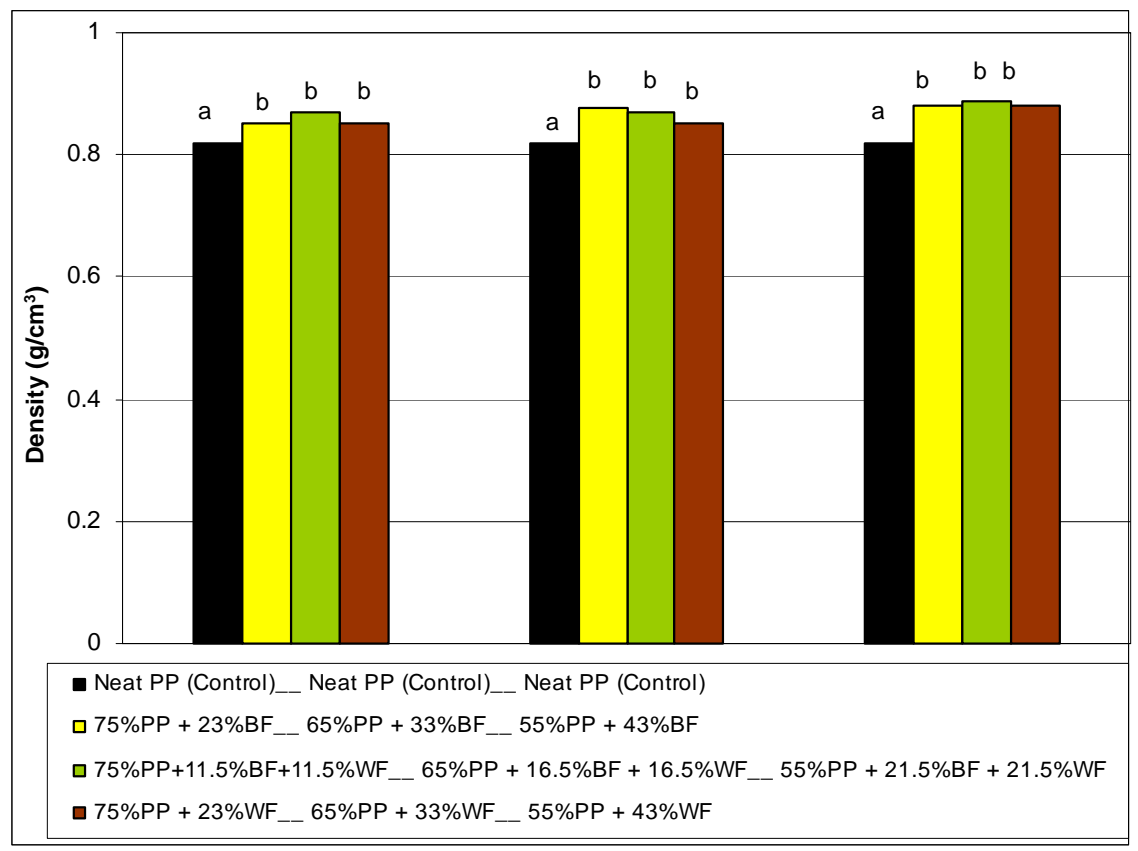

Figure 7. Mean values of the density of BF/PP, BF/WF/PP, and WF/PP composites. Duncan's multiple range tests are shown at the top of the columns. The different alphabetical designations indicate that there is a significant difference between different treatments (composites), whereas the common alphabetical designation indicates no significant difference $(P<0.05)$.

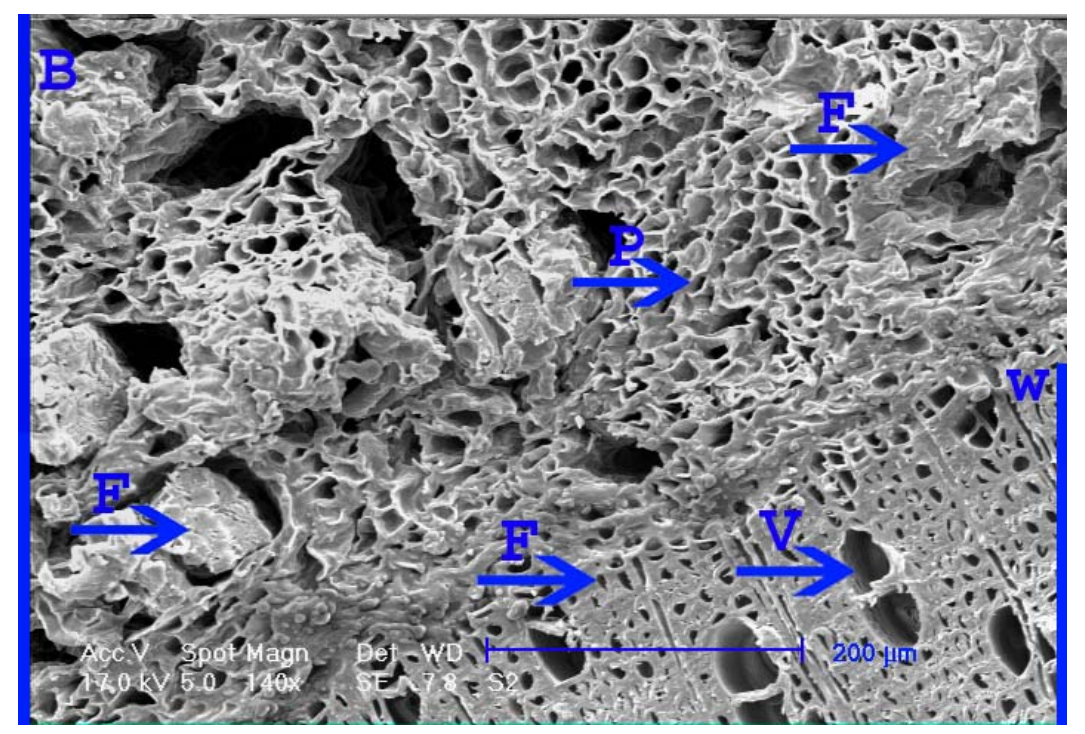

Figure 8. SEM micrograph of the natural wood (W) and inner bark (B) of poplar. The fibers (F) frequency in bark is not as much as wood and fibers alternate with phloem and parenchyma zone in bark. Most of the cells in bark are paranchymatous cells $(P)$ and thinner than wood, so BF have more fines than WF. 


\section{SEM Images of Wood and Bark and Fracture Surface of Composites}

In contrast to the bark, most cells in wood or xylem tissue are fibrous. However bark is made up of paranchymatous ground tissue; the cells are short and thin. It is due to this characteristic that the BF was much finer than WF. The bark fibers are not as abundant as the woody parts; they are much shorter and thicker than wood fibers and their aspect ratios (fiber length/fiber width) are not as high as wood fibers (see Table 2 and Figs. 8 and 9).
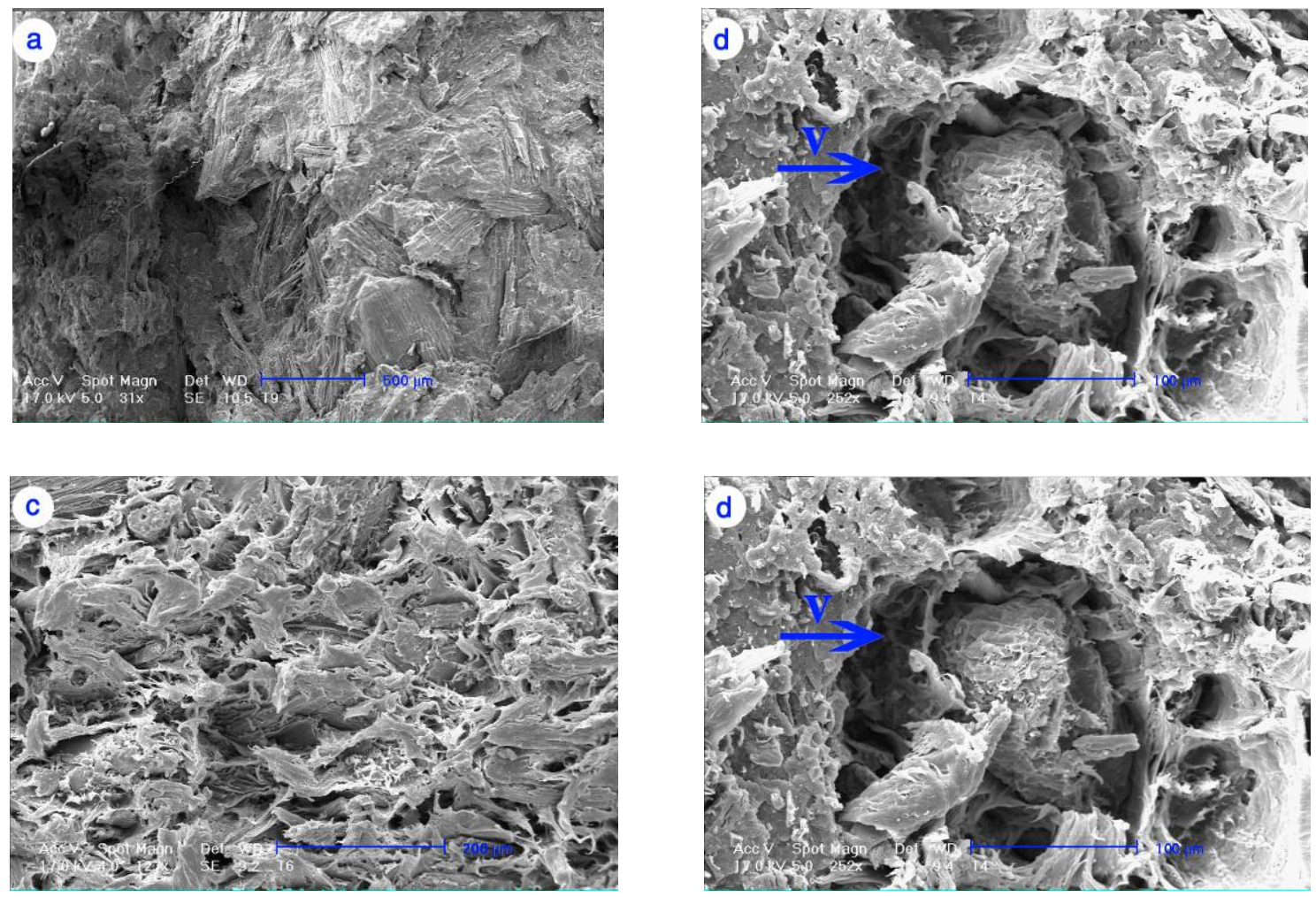

Figure 9. Fracture surface of flexural samples of some compositions: (a) $55 \%$ PP $+43 \%$ WF; (b) $75 \% \mathrm{PP}+23 \% \mathrm{BF}$; (c) $55 \% \mathrm{PP}+21.5 \% \mathrm{BF}+21.5 \% \mathrm{WF}$, and (d) $75 \% \mathrm{PP}+11.5 \% \mathrm{BF}+11.5 \%$ WF. By increasing the WF content the proportion of fines is reduced, the dispersion of flour gets better ( $\mathrm{a} \& \mathrm{c}$ ), the presence of bark causes voids (V), and delamination in composites and strength are reduced ( $b$ and $d)$. By increasing WF and BF contents, the dispersion of fillers gets better, voids decrease, and strength increases in composites ( $a$ \& $c$ ).

\section{CONCLUSIONS}

1. Both $\mathrm{BF}$ and $\mathrm{WF}$ composites exhibited significantly increased mechanical strength, i.e. MOR, MOE, tensile modulus, and tensile strength in comparison to neat polypropylene. However the notched impact strength was reduced.

2. Despite the increase in mechanical strength, the effect of BF on mechanical strength was significant in comparison to neat PP, but its effectiveness was minor. However 
by adding WF to the composites, the mechanical characteristics recovered significantly but never approached those of the composite made with WF/PP.

3. Composites made with BF exhibited lower mechanical strength compared to those made with WF. Differences in chemical composition between bark and wood, fines and low slenderness ratio of $\mathrm{BF}$, poor dispersion of $\mathrm{BF}$, and also the lower intrinsic fiber strength of bark fibers compared to wood fibers are the main reasons for this demarcation.

4. The effect of fiber content on mechanical strength is positive for composites made with $\mathrm{WF} / \mathrm{BF} / \mathrm{PP}$ and $\mathrm{WF} / \mathrm{PP}$ and negative for those composite made with BF/PP. Thus the effect of fiber content on mechanical properties is dependent on the intrinsic fiber characteristics.

5. The BF alone cannot reinforce the polypropylene composite suitably and it is better to be blended with WF.

6. The negative correlation between notched impact strength and composite which is reinforced with $\mathrm{WF}$ and $\mathrm{BF}$ is similar to other lignocellulosic material and this is because lignocellulosic fillers makes PP more brittle and less energy is needed to initiate a crack in the sample.

\section{ACKNOWLEDGMENTS}

The authors are grateful for the support of the Department of Wood Science and Technology, Karaj Branch, Islamic Azad University. This article is extracted from Hamed Khodadadi’s M.S. dissertation.

\section{REFERENCES CITED}

Basiji, F., Safdari, V., Nourbakhsh, A., and Pilla, S. (2010). “The effects of fiber length and fiber loading on the mechanical properties of wood-plastic (polypropylene) composites,” J. Turk. Agric. For. 34, 191-196.

Blanchet, P., Cloutier, A., and Riedl, B. (2000). "Particleboard made from hammer milled black spruce bark residues,” Wood Science and Technology 34(1), 11-9.

Bledzki, A. K., Gassan, J., and Theis, S. (1998). "Wood-filled thermoplastic composites," J. Mechanics of Composite Materials 34(6), 563-568.

Bledzki, A. K., Faruk, O., and, Huque, M. (2002). "Physico-mechanical studies of wood fiber reinforced composites,” J. Polymer-Plastics Technol. Eng. 3(41), 435-451.

Bouafif, H., Koubaa, A., Perre, P., Cloutier, A., and Riedl, B. (2008). "Analysis of among-species variability in wood fiber surface using DRIFTS and XPS: Effects on esterification efficiency,” J. Wood Chemistry and Technology 28(4), 296-315.

Bouafif, H., Koubaa, A., Perre, P., and Cloutier, A. (2009). "Effects of fiber characteristics on the physical and mechanical properties of wood plastic composites,” Part A, J. Composites: Appl. Sci. Manuf. 40(12), 1975-1981.

Exley, R. R., Butterfield, B. G., and Meylan, M. A. (1974). "Preparation of wood specimens for SEM,” J. Microscopy 101(1), 21. 
Gamstedt, K. E., Nygard, P., and Lindström, M. (2007). “Transfer of knowledge from papermaking to manufacture of composite materials,” In: Proc. 3e symposium international sur les composites bois polymères, Bordeaux, France, 26-27.

Harkin, J. M., and Rowe, J. M. (1971). “Bark and its possible uses,” USDA For. Serv. For. Prod. Lab. Res. Note FPl-091.

Harper, D. P. and Eberhardt, T. L. (2010). "Evaluation of micron-sized wood and bark particles as filler in thermoplastic composites," 10th International Conference on Wood \& Biofiber Plastic Composites. Madison, WI: Forest Prod. Soc., 248-252.

Kazemi Najafi, S., Kiaefar, A., and Tajvidi, M. (2008). "Effect of bark flour content on the hygroscopic characteristics of wood-polypropylene composites,” J. Applied Polymer Science 110(5), 3116-3120.

Klasnja, B., Kopitovic, S., and Orlovic, S. (2002). "Wood and bark of some poplar and willow clones as fuelwood,” J. Biomass and Bioenergy 23(6), 427-432.

Lu, J. Z., Wu, Q., and Negulescu, I. I. (2005). "Wood-fiber/high-density-polyethylene composites: Coupling agent performance,” J. Applied Polymer Science 96(1), 93-102.

Migneault, S., Koubaa, A., Erchiqui, F., Chaala, A., Englund, K., and Wolcott, M. P. (2009). "Effects of processing method and fiber size on the structure and properties of wood-plastic composites,” Part A, J. Compos. Appl. Sci. Manuf 40(1), 80-85.

Rowell, R. M., Sanadi, A. R., Caulfield, D. F., and Jacobson, E. (1997). "Utilization of natural fibers in plastic composites: Problems and opportunities,” In: Leão, A. L., Carvalho, F. X., and Frollini, E. (eds.), Lignocellulosic-Plastic Composites, São Paulo, USP \& UNESP, 23-51.

Saputra, H., Simonsen, J., and Li, K. (2004). "Effect of extractives on the flexural properties of wood/plastic composites,” Composite Interfaces 11(7), 515-524.

Stark, N. M., and Berger M. J. (1997). “ Effect of particle size on properties of woodflour reinforced composites,” 4th Intl. Conf. Wood Fiber-plastic Compos., Madison.

Stark, N. M., and Rowlands, R. E. (2003). "Effects of wood fiber characteristics on mechanical properties of wood/polypropylene composites,” J. Wood Fiber Science 35(2), 167-74.

Wang, X., Wang, Q., Xu, G. J., and Xu, L. S. (1999). “Antioxidant properties and structure analysis of phenolic glucoides from bark of Populus ussuriensis Kom,” Wood Science and Technology 45(1), 5-13.

Xing, C., Deng, J., Zhang, SY., Riedl, B., and Cloutier, A. (2006). “Impact of bark content on the properties of medium density fiberboard (MDF) in four species grown in Eastern Canada,” J. Forest Product 56(3), 64-69.

Yemele, M. C. N., Koubaa, A., Blanchet, P., Cloutier, A., and Wolcott M. (2008). "Effects of bark content and particle geometry on the physical and mechanical properties of particleboard made from black spruce,” J. Forest Product 58(11), 48-56.

Yemele, M. C. N., Koubaa, A., Cloutier, A., Soulounganga, P., and Koubaa, A. (2010). "Effect of bark fiber content and size on the mechanical properties of bark/HDPE composites,” Part A, J. Applied Science and Manufacturing 41(1), 131-137.

Article submitted: July 29, 2011; Peer review completed: September 24, 2011; Revised version received and accepted: October 27, 2011; Published: November 1, 2011. 